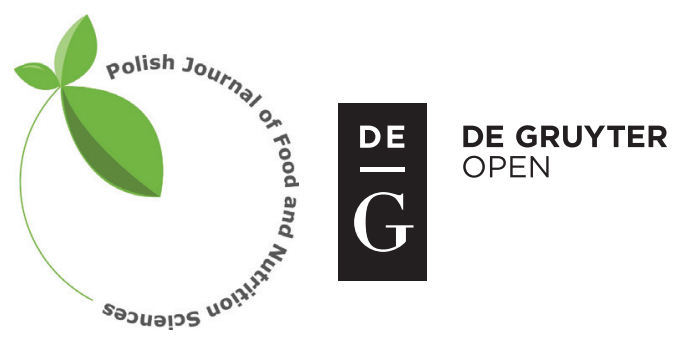

Pol. J. Food Nutr. Sci., 2016, Vol. 66, No. 1, pp. 57-60 DOI: $10.1515 /$ pjfns-2015-0017 http://journal.pan.olsztyn.pl

Short report

Section: Food Quality and Functionality

\title{
Evaluation of Malathion and Malaoxon Contamination in Buffalo and Cow Milk from Afyonkarahisar Region, Turkey, Using Liquid Chromatography/Tandem Mass Spectrometry - a Short Report
}

\author{
Recep Kara ${ }^{1 *}$, Sinan Ince ${ }^{2}$ \\ ${ }^{1}$ Afyon Kocatepe University, Faculty of Veterinary Medicine, Department of Food Hygiene and Technology, \\ 03200, ANS Campus, Afyonkarahisar, Turkey \\ ${ }^{2}$ Afyon Kocatepe University, Faculty of Veterinary Medicine, Department of Pharmacology and Toxicology, \\ 03200, ANS Campus, Afyonkarahisar, Turkey
}

Key words: buffalo milk, cow milk, malathion, malaoxon, LC/MS/MS

Organophosphate (OP) pesticides via consumption of milk and milk products induce hazardous effects on human health. Considering their risk to human health, the determination of organophosphate pesticide levels in dairy products is very important. Until now, there has been limited data available on the occurrence of organophosphate pesticides in dairy products in Turkey. The aim of the present study was to investigate the presence of malathion and malaoxon residues in commonly consumed buffalo and cow milk products in the city of Afyonkarahisar, Western Turkey. For this purpose, 75 buffalo and 75 cow milk samples were collected from the city. Malathion and malaoxon levels were determined by means of liquid chromatography/ tandem mass spectrometry. In the study, neither malathion nor malaoxan was detected in buffalo and cow milk samples. In conclusion, survey studies were performed continuously for organophosphate pesticide contamination in consumed milk samples and products in Turkey.

\section{INTRODUCTION}

Milk and its products play a very important role in human nutrition. Milk has a significantly elevated chemical composition and content of conjugated linoleic acid, macroelements, microelements [Nalecz-Tarwacka et al., 2003; Barlowska et al., 2006], good microbiological and cytological quality [Czerniewicz et al., 2006]. Detected pesticide residues in foods are considered hazardous for the consumer health, also consumption of foods containing residues is not safe for humans [Pico et al., 2006]. Furthermore, food-processing methods such as pasteurization, sterilization, ultra-high temperatures, and fermentation could not eradicate pesticide residues in milk or its products [Steinhart et al., 1996].

Pesticides, toxic and carcinogenic compounds, could cause very serious health problems for both animals and humans as well as the environmental problems [Safe, 1992]. Also, they have caused environmental and health problems in many countries [Aktar et al., 2009]. In addition to this, pesticide poisoning causes more deaths than infectious diseases in developing countries [Eddleston et al., 2002]. Malathion, an OP having high selective toxicity, is widely used in agriculture throughout the world [Bonilla et al., 2008]. It is widely used in control of many insects and agriculture [Nair \& Pradeep, 2007]. When malathion is consumed, it is quickly converted

\footnotetext{
* Corresponding Author: Tel.: +902722281312; Fax:+902722281349;

E-mail: recepkara@aku.edu.tr (R. Kara)
}

to malaoxon and is metabolized by carboxylesterases within an organism [Cannon el al., 1996].

Residues of OP should be strictly controlled and tested on a routine basis for the residue of OP. The purpose of this study was to investigate the presence of malathion and malaoxon in both cow and buffalo milk samples and to evaluate them in terms of consumer health.

\section{MATERIALS AND METHOD}

\section{Chemicals}

The standard for malathion and malaoxon, ammonium acetate, and high-performance liquid chromatography (HPLC)-grade acetonitrile were obtained from Sigma Aldrich (Interlab A.S., Istanbul, Turkey). Pure water was purified with a PureLab-Q system and the cartridge column of LC 140 was purchased from ELGA, (Marlow, UK).

\section{Milk samples and extraction}

A total of 150 milk samples including 75 buffalo and 75 cow milk samples were obtained from Afyonkarahisar province and different districts during August 2012 and January 2013. The samples were transported to the laboratory inside a portable refrigerator, stored at $-20^{\circ} \mathrm{C}$ and tested for the presence of malathion and malaoxon. Milk sample extractions were carried out according to validated methods reported by Lehotay et al. [2005]. Briefly, $1 \mathrm{~mL}$ sample was put into a $50 \mathrm{~mL}$ centrifuge tube, followed by adding $15 \mathrm{~mL}$ of ace- 

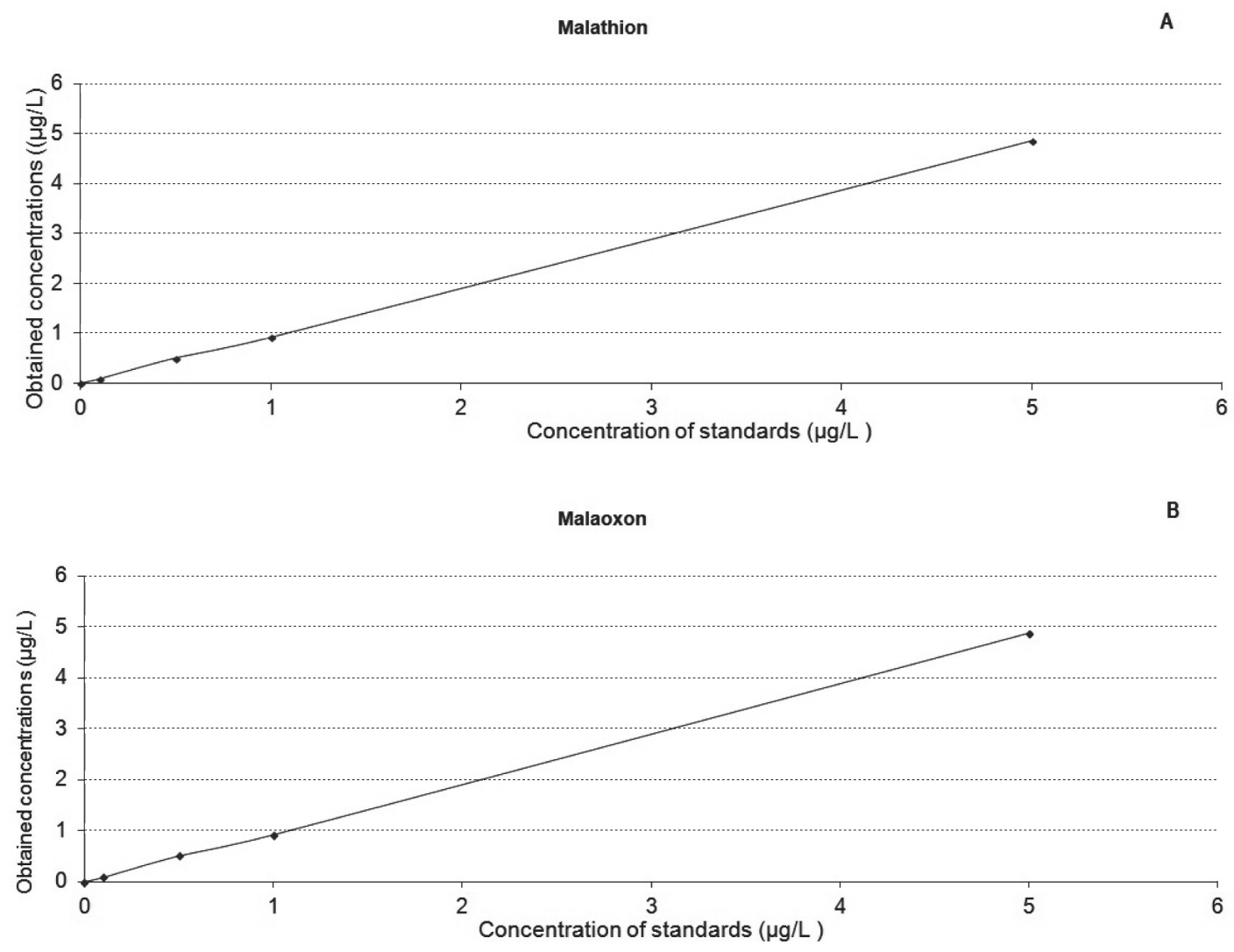

FIGURE 1. The linearity of malathion (A) and malaoxon (B) calibration curve from peak area calculations after five injections ranging from 0.01 to $5 \mu \mathrm{g} / \mathrm{L}$ of standard solutions in LC/MS/MS.

tonitrile containing $1 \%$ acetic acid. After shaking for $5 \mathrm{~min}$, $2.5 \mathrm{~g}$ anhydrous $\mathrm{MgSO}_{4}$ plus sodium acetate was added into the tube. The mixed solution was centrifuged for $5 \mathrm{~min}$ at $1650 \times \mathrm{g}$ and then $6 \mathrm{~mL}$ of supernatant was transferred into a $15 \mathrm{~mL}$ tube (containing $300 \mathrm{mg}$ of primary secondary amine sorbent plus $1.8 \mathrm{~g}$ of anhydrous $\mathrm{MgSO}_{4}$, which constituted a cleanup procedure called dispersive solid-phase extraction). Similarly, the solution was centrifuged for $5 \mathrm{~min}$ at $1650 \times \mathrm{g}$ and then $1 \mathrm{~mL}$ of supernatant was transferred into auto sampler vials for analysis by liquid chromatography/tandem mass spectrometry (LC/MS/MS).

\section{Standard preparation and calibration}

The malathion and malaoxon standards were dissolved in acetonitrile at $1 \mathrm{mg} / \mathrm{L}$ and were stored at $4^{\circ} \mathrm{C}$ in the dark until use. To prepare the working standard for analysis, malathion and malaoxon stock solutions were equally pipetted and transferred into a vial, and they were diluted with the mobile phase. The final concentration of malathion and malaoxon was $1 \mu \mathrm{g} / \mathrm{L}$. The linearity of calibration curve was evaluated from peak area calculations after five injections of standard solutions prepared in acetonitrile at 0.01, 0.1, $0.5,1$ and $5 \mu \mathrm{g} / \mathrm{L}$ concentrations (Figure $1 \mathrm{~A}$ and Figure 1B). The limit of detection (LOD) was calculated from the relative standard deviation (RSD) of average detector responses of ten replicate injections, via the formula LOD $=3 \times \mathrm{RSD} \times$ concentration (provided that the response of the blank was zero). From these calculated values, a best estimated, rounded LOD value was established. The estimated limit of quantification
(LOQ) was calculated by LOQ $=10 \times \mathrm{RSD} \times$ concentration. The analytical methods used in this trial were evaluated using milk samples spiked with malathion and malaoxon at levels of $0.01-5 \mu \mathrm{g} / \mathrm{L}$ (n: 5 per spiking level).

\section{Instrument and conditions}

The LC/MS/MS analysis was performed by an Agilent 1200 series LC system (Agilent Technologies, Waldbronn, Germany), consisting of a binary high-pressure gradient pump. LC separation was performed on a $2.1 \times 100 \mathrm{~mm}$ i.d. column packed with $2.7 \mu \mathrm{m}$ Proshell 120 SB C18 (Agilent Technologies, Santa Clara, CA, USA) at $35^{\circ} \mathrm{C}$. The mobile phases were: aqueous $0.4 \mathrm{mmol} / \mathrm{L}$ ammonium formamide and $0.2 \mathrm{~mL}$ formic acid in water (solvent A) and acetonitrile (solvent B). The column gradient program was used consisting of $20 \% \mathrm{~A}$ and $80 \% \mathrm{~B}$ ramped linearly over the course of $12 \mathrm{~min}$ to $100 \%$. After analysis, the column was re-equilibrated for $15 \mathrm{~min}$ at the initial mobile phase composition. The flow rate of the mobile phase was set at $0.35 \mathrm{~mL} / \mathrm{min}$ and the injection volume was $2 \mu \mathrm{L}$.

The mass spectrometry was performed using an Agilent 6460 LC/MS Triple Quadrupole instrument equipped with an ESI source (Agilent Technologies, Waldbronn, Germany). The nebulizer and drying gas $\left(350^{\circ} \mathrm{C}\right)$ were obtained with a nitrogen generator (Balston, Haverhill, MA, USA). The capillary voltage for ion transmission, fragmentor voltage for in-source-fragmentation, and vaporizer temperature were all optimized using the analytical column with malathion and malaoxon standard at $0.01 \mu \mathrm{g} / \mathrm{L}$. Nebulizer gas, 
TABLE 1. Mass chromatogram results of malathion and malaoxon in solvent at $0.01-5 \mu \mathrm{g} / \mathrm{L}$ with ESI

\begin{tabular}{l|c|c|c|c|c|c|c|c}
\hline \multirow{2}{*}{$\begin{array}{l}\text { Concentration } \\
\mu \mathrm{g} / \mathrm{L})\end{array}$} & \multicolumn{2}{|c|}{ Response } & \multicolumn{2}{c|}{ RF value } & \multicolumn{2}{c|}{ RT (min) } & \multicolumn{3}{c}{ Accuracy $(\%)$} \\
\cline { 2 - 9 } 0.01 & Malathion & Malaoxon & Malathion & Malaoxon & Malathion & Malaoxon & Malathion & Malaoxon \\
\hline 0.1 & 164379 & 276172 & 16487.92 & 27617.22 & 5.476 & 4.370 & 72.91 & 88.34 \\
0.5 & 1311597 & 2454642 & 13115.97 & 24546.42 & 5.476 & 4.370 & 88.28 & 92.24 \\
1 & 10612743 & 16571052 & 21225.49 & 33142.10 & 5.476 & 4.370 & 107.55 & 109.48 \\
5 & 19538317 & 29541506 & 19538.32 & 29541.51 & 5.476 & 4.370 & 98.38 & 97.85 \\
\hline
\end{tabular}

Note: RF, radio frequency; RT, retention time.
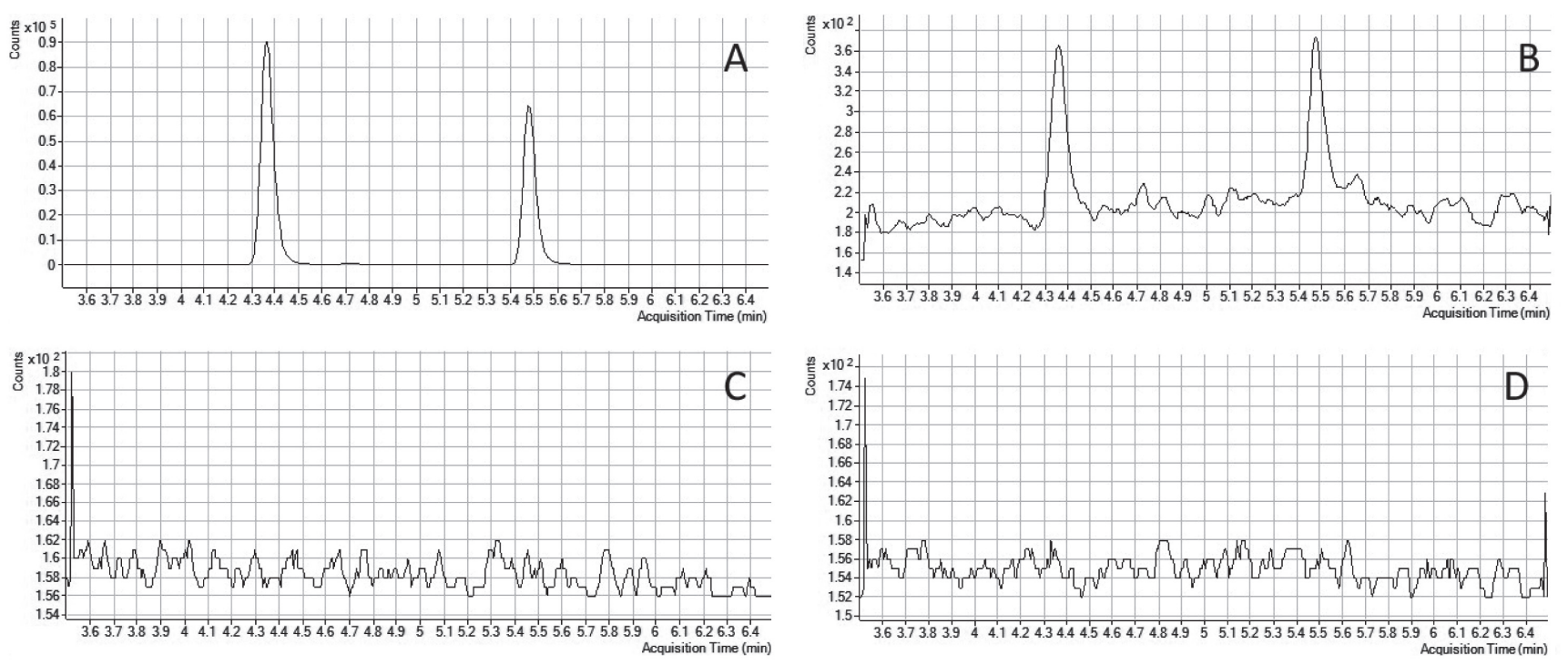

FIGURE 2. Malathion and malaoxon chromatogram graphics; standards $(0.01 \mu \mathrm{g} / \mathrm{L})(\mathrm{A})$, milk sample spiked with $0.05 \mu \mathrm{g} / \mathrm{L}$ malathion and malaoxon (B), cow milk samples (C), and buffalo milk samples (D).

drying gas, capillary voltage and vaporizer temperature were set at $45 \mathrm{psi}, 11 \mathrm{~L} / \mathrm{min}, 3000 \mathrm{~V}$, and $400^{\circ} \mathrm{C}$, respectively. Quantitative analysis was carried out in selective reaction monitoring mode. Malathion and malaoxon retention times were 5.476 and 4.370. Their molecular weights, precursor ions $(\mathrm{m} / \mathrm{z})$, and product ions $(\mathrm{m} / \mathrm{z})$ were $330,331,285$, and 314 , 315,127 ; respectively.

\section{RESULTS AND DISCUSSION}

Calibration curves for quantification of the standard showed good linearity with correlation coefficients $\left(\mathrm{r}^{2}\right)$ $>0.999$ over the range studied by ESI mode (Table 1). The LOD, LOQ, and RSD of malathion and malaoxon in milk samples using LC/MS/MS were $0.01,0.04 \mu \mathrm{g} / \mathrm{L}$, and $4.79 \%$, respectively. Samples with malathion and malaoxon levels below $0.01 \mu \mathrm{g} / \mathrm{L}$ were considered negative. Recovery of malathion and malaoxon was $94 \%$ and $96 \%$, respectively. Malathion and malaoxon chromatogram analyses of standard $(0.01 \mu \mathrm{g} / \mathrm{L})$, spiked $(0.05 \mu \mathrm{g} / \mathrm{L})$, and buffalo and cow milk samples were shown in Figure 2A-D, respectively.

Some researchers reported that milk and its products were contaminated with OP. In the Agreste region of Pernambuco,
Brazil, 30 raw milk samples and all components of the animal diet were collected from several farms. Among the thirty milk samples analyzed by gas chromatography (GC), six samples (20\%) were contaminated with OP, five samples (16.7\%) with carbamate, and one sample with both pesticides [Fagnani et al., 2011]. Melgar et al. [2010] investigated OP residues in raw milk and infant formulas from northwest Spain. A total of 312 samples were collected (70 from infant formulas and 242 from raw milk) biweekly during a 24-month period, analyzed by $\mathrm{GC}$ with a nitrogen-phosphorus detector. The detectable levels of OP residues were found in $6.73 \%$ of whole milk and in $8.67 \%$ of raw milk samples. The highest percentage incidence measured was for dichlorvos (5.78\%), followed by coumaphos $(2.06 \%)$, and parathion methyl $(0.83 \%)$. In conclusion, no residue was detected in the final product (infant formulas), so any risk to consumer health, especially to children's health, would be limited. Also, Pagliuca et al. [2006] determined the contamination in raw milk in terms of OP used in Italy. Among the 135 samples analyzed by GC, 10 samples showed an OP contamination ranging from 5 to $18 \mu \mathrm{g} / \mathrm{kg}$. The higher results were recorded in the samples collected during the autumn-winter period and the main pollutants detected were acephate and chlorpyriphos. Also, Alder 
et al. [2006] evaluated the capabilities of MS in combination with $\mathrm{GC}$ and $\mathrm{LC}$ for the determination of a multitude of pesticides. They suggested that only for one substance class, the organochlorine pesticides, GC-MS achieved better performance. For all other classes of pesticides, the assessment showed a wider scope and better sensitivity if detection was based on LC-MS.

In this study, malathion and malaoxon residues were not detected in raw buffalo and cow milk samples from Afyonkarahisar province. Similarly, Keskin \& Kaya [2009] reported that OP residues were not detected in raw milk in Turkey. Zhao et al. [2012] reported that OP residues were detected at levels of $0.006-0.048 \mathrm{mg} / \mathrm{kg}$ in raw cow milk in Heilongjiang, China. In addition, Maver et al. [2007] noted that OP residues were found in $8.2 \%$ of non-animal origin products (vegetable, fruits, grains, alcohol drinks); however, they were not detected in animal-origin foods (liver, fish, eggs, honey, and milk) in Slovenia. The differences between this study and other studies might stem from the region, the contamination level of OP, animal feedstuff and its source, or from the use of different analytical methods.

\section{CONCLUSIONS}

Pesticides especially OP are often used in Turkey. Their common and unconscious handling by agricultural workers has the potential risk to public health. This is the first study to determine malathion and malaoxon in cow and buffalo milk in Afyonkarahisar. In this context, malathion- and malaoxon-contaminated milk should be considered carefully by manufacturers and consumers. To produce milk and milk products free from OP residues, is important for dairy sector. Also, auto-control strategies should be implemented in addition to strict government controls. Furthermore, consumers should be educated about the risks of pesticide contamination in milk and its products.

\section{ACKNOWLEDGEMENTS}

This study was supported by a grant from the Afyon Kocatepe University Scientific Research Council, Afyonkarahisar, Turkey (Project Code: 13.HIZ.DES.49).

\section{REFERENCES}

1. Aktar W., Sengupta D., Chowdhury A., Impact of pesticides use in agriculture: their benefits and hazards. Interdisc. Toxicol., 2009, 2, 1-12.

2. Alder, L., Greulich K., Kempe G., Vieth B., Residue analysis of 500 high priority pesticides: better by GC-MS or LC-MS/ MS. Mass Spectrom. Rev., 2006, 25, 838-865.

3. Barlowska J., Litwinczuk Z., Krol J., Kedzierska-Matysek M., Fatty acid profile and minerals content in milk from cows of various breeds over spring-summer feeding period. Pol. J. Food Nutr. Sci., 2006, 15/56, 13-16.

4. Bonilla E., Hernández F., Cortés L., Mendoza M., Mejía J., Carrillo E., Casas E., Betancourt M., Effects of the insecticides malathion and diazinon on the early oogenesis in mice in vitro. Environ. Toxicol., 2008, 23, 240-245.

5. Cannon J.M., Reddy V., Murrill E., Characterization of malathion residues in dairy goats and poultry. J. Agric. Food Chem., 1996,44,3365-3373.

6. Czerniewicz M., Kielczewska K., Kruk A., Comparison of some physicochemical properties of milk from holstein-friesian and jersey cows. Pol. J. Food Nutr. Sci., 2006, 15/56, 61-64.

7. Eddleston M., Karalliedde L., Buckley N., Fernando R., Hutchinson G., Isbister G., Konradsen F., Murray D., Piola J.C., Senanayake N., Sheriff R., Singh S., Siwach S.B., Smit L., Pesticide poisoning in the developing world-a minimum pesticides list. The Lancet, 2002, 360, 1163-1167.

8. Fagnani R., Beloti V., Battaglini A.P.P., Dunga K.S., Tamanini R., Organophosphorus and carbamates residues in milk and feedstuff supplied to dairy cattle.Pesq. Vet. Bras. 2011, 31(7), 598-602 .

9. Keskin F.I., Kaya S., Investigation of some organophosphorus insecticide residues in raw milk in Turkey. J. Etlik Vet. Micro., 2009, 20 (1-2), 1-10.

10. Lehotay S.J., De KokA.,HiemstraM., Van Bodegraven P., Validation of a fast and easy method for the determination of residues from 229 pesticides in fruits and vegetables using gas and liquid chromatography and mass spectrometric detection. J. AOAC Int., 2005, 88, 595-614.

11. Maver L., Stajnbaher D., Gros L., Kahne-Jurisevic B., Repse B., Sinigoj-Gacnik K., Residues of organophosphorus pesticides in different food commodities in Slovenia, 1997-1998. Inter. J. Environ. Poll., 2007, 31, 142-154.

12. Melgar M.J., Santaeufemia M., García M.A. Organophosphorus pesticide residues in raw milk and infant formulas from Spanish northwest. J.Env. Sci. Health, Part B: Pesticides, Food Contam. Agric. Wastes, 2010, 45, 595-600.

13. Nair S., Pradeep T., Extraction of chlorpyrifos and malathion from water by metal nanoparticles. J. Nanosci. Nanotechnol., 2007, 7, 1871-1877

14. Nalecz-Tarwacka T., Karaszewska A., Zdziarski K., The influence of carrot addition to cowõs ration on the level of vitamins and fatty acids in cow milk. Pol. J. Food Nutr. Sci., 2003, 12/53 (2), 53-56.

15. Pagliuca G., SerrainoA., GazzottiT., ZironiE., BorsariA., Rosmini R., Organophosphorus pesticides residues in Italian raw milk. J. Dairy Res, 2006, 73, 340-344.

16. Pico Y., Font G., Jose-Ruiz M., Fernandez M., Control of pesticide residues by liquid chromatography-mass spectrometry to ensure food safety. Mass Spectr. Rev., 2006, 25, 917- 960.

17. Safe S., Development, validation and limitations of toxic equivalency factors. Chemosphere, 1992, 25: 61 - 64.

18. Steinhart C.E., Doyle M.E., Cochrane B.A. (eds.). Food Safety. 1996. Marcel Dekker, New York, pp. 376-394.

19. Zhao X.H., Bo L.Y., Wang J., Li T.J., Survey of seven organophosphorus pesticides in drinking water, feedstuffs and raw milk from dairy farms in the Province Heilongiiang during 2008-2009. Milchwissenschaft, 2012, 67, 293-296.

Submitted: 25 September 2014. Revised: 23 December 2014. Accepted: 23 January 2015. Published on line: 25 November 2015. 